\title{
Performance prediction of porous bed solar air heater using MLP and GRNN model- A comparative study
}

\author{
Harish Kumar Ghritlahre \\ Department of Energy and Environmental Engineering, Chhattisgarh Swami Vivekanand Technical University, \\ Newai, Chhattisgarh, 491107, India. \\ E-mail address: harish.ghritlahre@gmail.com \\ Received July 1, 2019; received in revised form July 5, 2019; Accepted July 5, 2019; Available online July 2019
}

\begin{abstract}
In present work, two different types of neural model have been used to predict the thermal performance of unidirectional flow porous bed solar air heater (SAH). These models are multi-layer perceptron (MLP) and generalized regression neural network (GRNN). Total 96 data were used in neural model. The neural model developed with six input parameters: mass flow rate, wind speed, ambient temperature, inlet air temperature, air mean temperature and solar intensity, thermal efficiency is used as output variable. In MLP model, LM with 13 neurons found to be an optimal model and in case of GRNN model, maximum accuracy in prediction has been obtained at spread value-0.8. The comparative analysis shows that the GRNN is the best model as compared to MLP due to less error and highest value of $R^{2}$. These results show that the GRNN model is appropriate model for predicting the thermal performance SAH.
\end{abstract}

Keywords: Solar air heater, Porous bed, Thermal performance, Artificial neural network.

\section{Introduction}

A solar air heater (SAH) is a special type of heat exchanger which absorbs solar radiations and transfers the absorbed thermal energy to the flowing air. The heated air is used for space heating in commercial and residential buildings. In addition to this, it is used for crop drying, timber seasoning and various low temperature heating applications. The thermal efficiency of a solar air heater is usually low because of the low heat transfer coefficient between the heat transfer surface and the flowing air which results higher heat losses to atmosphere [1-2].Several methods have been employed to enhance the thermal efficiency of the solar air heater [3-6]. Packed bed solar air heater is one of the types of
SAHs, in which incident solar radiations penetrate to a greater depth and are absorbed gradually depending on the density of packing material. Porous absorber has high heat transfer surface area density and hence high heat transfer rate resulting in an increase in thermal efficiency of the solar air heater.

A variety of designs have been used in packed bed solar air heaters such as slit- and expanded aluminum foil matrix [3], wire screen matrix [4-6], glass beads [7] etc. for enhancement of the thermal efficiency of solar air heater. In these designs, solar radiation is absorbed in depth and results in relatively low temperature of absorber at the top of the packing, which decreases the heat losses from the absorber to ambient air and hence increases the thermal efficiency of the 
solar air heaters. The thermal performance of packed bed solar air heater is enhanced by the use of different geometrical and thermo physical characteristics of packed bed materials [7-10].

Table 1 Summary of neural technique used by various researchers.

\begin{tabular}{|c|c|c|c|}
\hline $\begin{array}{l}\text { Sr. } \\
\text { No } \\
\end{array}$ & $\begin{array}{l}\text { Technique } \\
\text { /models }\end{array}$ & Applied area & References \\
\hline 1 & MLP & $\begin{array}{l}\text { Atmospheric } \\
\text { sciences }\end{array}$ & $\begin{array}{l}\text { Gardner and } \\
\text { Dorling [11] } \\
\end{array}$ \\
\hline 2 & GRNN & $\begin{array}{l}\text { Cooling loads } \\
\text { for Buildings }\end{array}$ & $\begin{array}{l}\text { Ben-Nakhi } \\
\text { and } \\
\text { Mahmoud } \\
\text { [12] }\end{array}$ \\
\hline 3 & $\begin{array}{ll}\text { MLP and } \\
\text { RBF }\end{array}$ & $\begin{array}{l}\text { Hybrid solar } \\
\text { collector }\end{array}$ & $\begin{array}{c}\text { Facao et al. } \\
{[13]}\end{array}$ \\
\hline 4 & \begin{tabular}{|lr} 
Six & different \\
types & of \\
neural models
\end{tabular} & $\begin{array}{l}\text { Flat plate } \\
\text { collector }\end{array}$ & $\begin{array}{c}\text { Kalogirou } \\
{[14]}\end{array}$ \\
\hline 5 & MLP & $\begin{array}{l}\text { Flat plate solar } \\
\text { collector }\end{array}$ & $\begin{array}{c}\text { Sozen et al. } \\
{[15]}\end{array}$ \\
\hline 6 & $\begin{array}{ll}\text { ANN and } \\
\text { MLR }\end{array}$ & solar dryer & $\begin{array}{c}\text { Kassem et al. } \\
{[16]}\end{array}$ \\
\hline 7 & $\begin{array}{ll}\text { MLP and } \\
\text { MLR }\end{array}$ & $\begin{array}{l}\text { SAH with two } \\
\text { types of } \\
\text { zigzagged } \\
\text { absorber plate }\end{array}$ & $\begin{array}{c}\text { Caner et al. } \\
{[17]}\end{array}$ \\
\hline 8 & MLP & $\begin{array}{l}\text { SAH with } \\
\text { trapeze and } \\
\text { corrugated } \\
\text { absorber plate }\end{array}$ & Benli [18] \\
\hline 9 & $\begin{array}{l}\text { MLP } \\
\text { MLR }\end{array}$ & Solar radiations & $\begin{array}{c}\text { Sahin et al. } \\
\text { [19] }\end{array}$ \\
\hline 10 & $\begin{array}{l}\text { MLP } \\
\text { MLR }\end{array}$ & Solar cooker & Cakmak [20] \\
\hline 11 & $\begin{array}{l}\text { MLP } \\
\text { MLR } \\
\end{array}$ & Solar radiations & $\begin{array}{c}\text { Citakoglu } \\
\text { [21] } \\
\end{array}$ \\
\hline 12 & $\begin{array}{l}\text { MLP and } \\
\text { MLR }\end{array}$ & Solar still & $\begin{array}{c}\text { Mashaly and } \\
\text { Alazba [22, } \\
23]\end{array}$ \\
\hline 13 & $\begin{array}{l}\text { MLP,GRNN, } \\
\text { RBF and } \\
\text { MLR }\end{array}$ & $\begin{array}{l}\text { Porous bed and } \\
\text { roughened } \\
\text { SAHs }\end{array}$ & $\begin{array}{c}\text { Ghritlahre } \\
\text { and Prasad } \\
{[24-34]}\end{array}$ \\
\hline
\end{tabular}

MLP: Multi-Layer Perceptron; MLR: Multiple Linear Regression; GRNN: Generalized Regression Neural Network; RBE: Radial Basis Function.

ANN is one of the most used soft computing techniques for the analysis of different types of thermal systems. This technique is used for optimization, modeling, simulation and estimation to solve complex problems which are difficult to solve by other conventional techniques [11, 25]. The use of ANN technique saves time and also provides key information patterns in a multi-dimensional information domain and, therefore, it has been becoming increasingly popular in Science and Engineering sectors. It has wide applications in the field of thermal engineering specially for prediction of performance of thermal systems including the solar energy systems. Many researchers have implemented neural technique in the past for prediction of performance energy systems. The summary of ANN technique used by various researchers is given in Table 1 .

In the present work, two different types of neural models were used to predict the thermal efficiency of porous bed SAH i.e. MLP and GRNN, using 96 data samples. The six parameters such as mass flow rate, wind speed, ambient temperature, inlet air temperature, mean fluid temperature and solar intensity selected as input parameters, and the thermal efficiency of SAH selected as output parameters. These input and output parameters have been used in GRNN, and MLP model. The results of neural models are compared on the basis of statistical error analysis. 


\section{Experimental system description and data collection}

Fig.1 shows schematic diagram of porous bed test sections of unidirectional flow. In unidirectional flow the directions of incident solar radiation and the flowing air in the porous bed are same [3, 6, 24]. The blackened wire-screens have been used as porous absorber. The exposed area of each of the solar collector test sections is $1.22 \mathrm{~m} \mathrm{x}$ $0.45 \mathrm{~m}$. Two types of wire screen matrices of the specifications, as given in Table 2 have been considered in the present study. Total 96 sample data have been collected for total 12 days, in which 48-48 samples are from porous absorber type A and type B. The data were collected for the parameters: mass flow rate, wind speed, atmospheric air temperature, inlet air temperature, mean air temperature and solar intensity in the open sky- days.

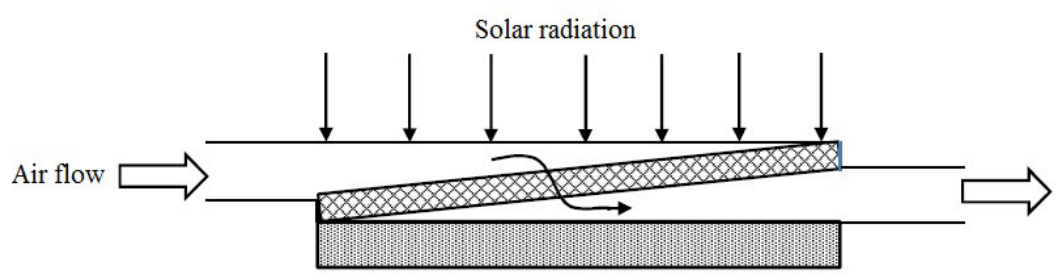

Figure 1 Schematic diagram of unidirectional flow porous bed solar air heater

Table 2 Detailed specification of the porous absorbers

\begin{tabular}{lrr}
\hline Absorber & Type A & Type B \\
\hline Mesh No. $\left(\mathrm{cm}^{-1}\right)$ & $4 \frac{1}{2} \times 4 \frac{1}{2}$ & $4 \times 4$ \\
$\begin{array}{l}\text { Wire diameter, bare } \\
(\mathrm{mm})\end{array}$ & 0.464 & 0.556 \\
Wire diameter, & 0.480 & 0.582 \\
painted (mm) & & \\
$\begin{array}{l}\text { Screen thickness } \\
\text { (mm) }\end{array}$ & 0.90 & 1.15 \\
Mesh pitch (mm) & 2.22 & 2.50 \\
Porosity & 0.925 & 0.915 \\
\hline
\end{tabular}

\section{Solar air heater performance}

Solar air heater performance is evaluated by thermal efficiency which is the ratio of solar energy absorbed by flowing air to solar energy received on the absorber area [1,2]. This is represented by following formula:

$$
\eta_{t h}=\frac{\dot{Q}_{u}}{\dot{Q}_{A}}
$$

The solar radiation incident on the absorber surface is expressed by

$$
\dot{Q}_{A}=I A_{p}
$$

where $I$ is the global solar irradiance and $A_{p}$ absorber plate area.

The useful solar energy gained by flowing air in the duct and it is written as

$$
\dot{Q}_{u}=\dot{m} C_{p f} \cdot \Delta T=\dot{m} C_{p f}\left(T_{o}-T_{i}\right)
$$

Finally, the performance of SAH is written by following equation $[1,2]$ :

$$
\eta_{t h}=\frac{m C_{p f}\left(T_{o}-T_{i}\right)}{I A_{p}}
$$

where $m$ is mass flow rate and $T_{o}$ and $T_{i}$ are the temperatures of outlet and inlet air respectively. 


\section{ANN and Performance Predicting Models}

\subsection{Artificial Neural Network (ANN)}

ANN is a computational technique which works like a human brain. It is a complex information processing system, which is structured from interconnected segmental processing elements called as neurons. The basic structure of artificial neuron is given in Fig.2. These neurons find the input information from other sources, perform generally a non-linear operation on the result and then give final results as output. ANN works in two ways, first learning and then storing the knowledge in interconnects called weights. ANN is a simulation tool which can be used to estimate the values on the basis of input parameters, optimum topology and training processes [35].

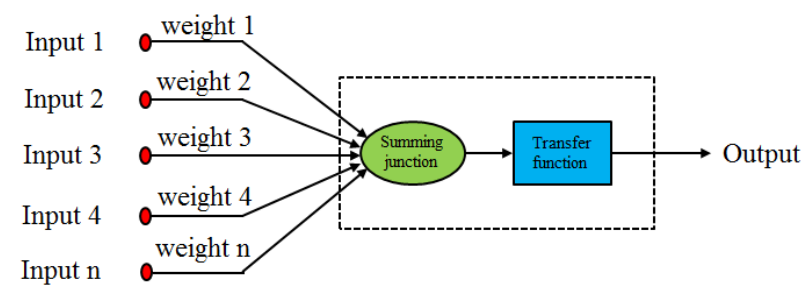

Figure 2 Basic structure of artificial neuron.

\subsubsection{Multi-Layer Perceptron (MLP)}

The basic structure of multi-layer perceptron (MLP) is shown in Fig 3. The MLP model consists of basically three layers: an input layer, one or more hidden layers and an output layer $[11,25]$ as shown in Fig.3. In feed forward networks, each product of input elements $\left(x_{i}\right)$ and weights $\left(w_{i j}\right)$ are fed to summing junctions and is summed with bias $\left(b_{j}\right)$ of neurons as follows:

$$
Y=\left(\sum_{i=1}^{n} w_{i j} x_{i}\right)+b_{j}
$$

Then this sum $Y$ passes through transfer function $F$ which generates an output.

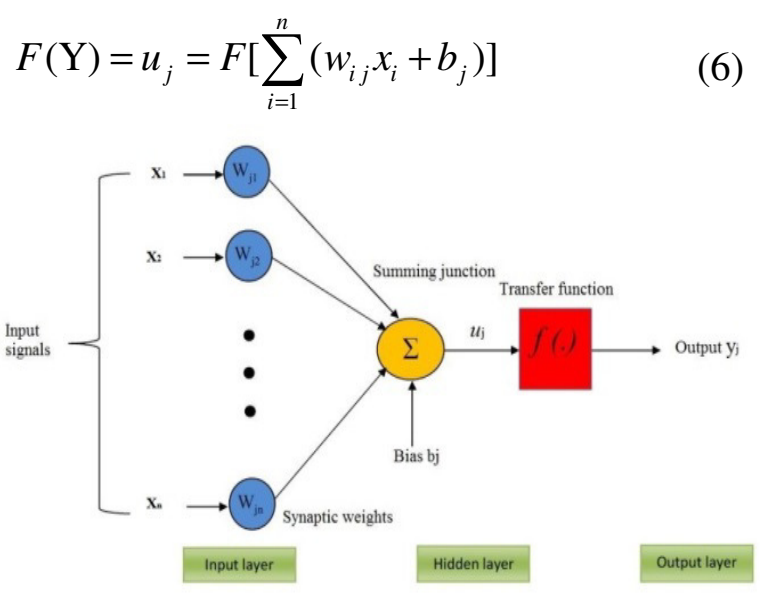

Figure 3 MLP neural network

Tansig and logsig are most commonly used transfer functions in hidden layer. The nonlinear activation function which is widely used is called as sigmoid function whose output lies in the mid of 0 and 1 , and the sigmoid transfer function is written as:

$$
F(\mathrm{Y})=\frac{1}{1+e^{-Y}}
$$

If the values of input and output layer are negative, then tansig transfer function is used.

$$
F(\mathrm{Y})=\frac{e^{Y}-e^{-Y}}{e^{Y}+e^{-Y}}
$$

The performance index of different training algorithm is mean square error (MSE) and it is formulated as

$$
M S E=\frac{1}{n} \sum_{i=1}^{n}\left(Y_{A}-Y_{P}\right)^{2}
$$

where, $Y_{A}$ is actual data and $Y_{P}$ is predicted data.

\subsubsection{Generalized Regression Neural Network (GRNN)}

Generalized regression neural network (GRNN) technique is based on probabilistic model. The basic structure of GRNN shown in Fig.4. The GRNN architecture consists of four layers: 
input layer, pattern layer, summation layer and output layer. The numbers of input variables depend on number of data sets observed from data collection in the input layer. The input layer collects information and transmits to the pattern layer. Pattern layer is used to perform clustering on the training process. Usually the number of pattern layer neurons is equal to the number of data sets of training pairs. Then it passes through summation layer. This layer consists of only two neurons: first and second neuron is called $D$ Summation and $S$ Summation neuron respectively. These two neurons in the summation layer give the following equation $[12,25]$ :

$$
D=\sum_{i=1}^{n} Y_{i} \exp \left(-\frac{\left(X-X_{i}\right)^{T}\left(X-X_{i}\right)}{2 \sigma^{2}}\right)
$$

and

$$
S=\sum_{i=1}^{n} \exp \left(-\frac{\left(X-X_{i}\right)^{T}\left(X-X_{i}\right)}{2 \sigma^{2}}\right)
$$

where, $X$ is input vector, $Y$ is output and $\sigma$ is smoothing factor.

The GRNN is a powerful tool for non- linear regression analysis. Thus, it is computes following function:

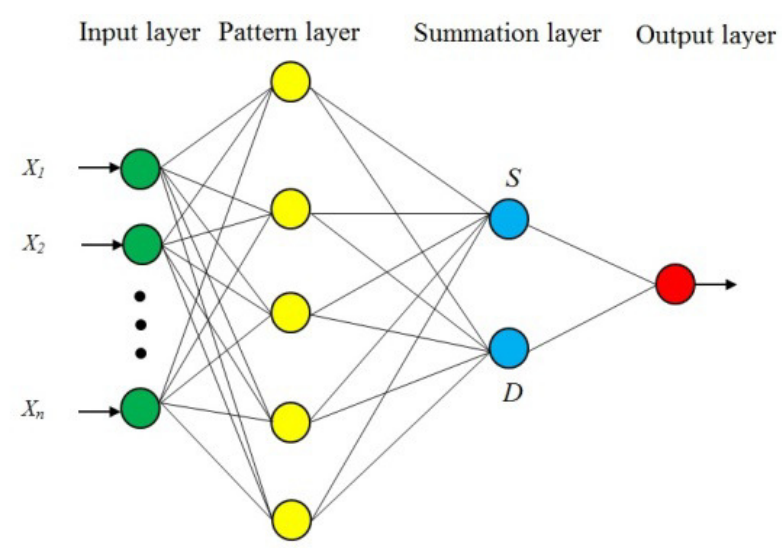

Figure 4 Basic structure of GRNN

$$
Y(X)=\frac{D}{S}=\frac{\sum_{i=1}^{n} Y_{i} \exp \left(-\frac{\left(X-X_{i}\right)^{T}\left(X-X_{i}\right)}{2 \sigma^{2}}\right)}{\sum_{i=1}^{n} \exp \left(-\frac{\left(X-X_{i}\right)^{T}\left(X-X_{i}\right)}{2 \sigma^{2}}\right)}
$$

\subsection{Performance criteria of model}

In this work, the performance analysis of MLP, and GRNN models are evaluated by the use of coefficient of determination $\left(R^{2}\right)$, root mean square error (RMSE), mean absolute error $(M A E)$ and model efficiency $(M E)$.

Root mean square error:

$$
R M S E=\sqrt{\frac{1}{n} \sum_{i=1}^{n}\left(Y_{A}-Y_{P}\right)^{2}}
$$

Coefficient of determination:

$$
R^{2}=1-\frac{\sum_{i=1}^{n}\left(Y_{A}-Y_{P}\right)^{2}}{\sum_{i=1}^{n} Y_{P}^{2}}
$$

Mean absolute error:

$$
\text { MAE }=\frac{1}{n} \sum_{i=1}^{n}\left(Y_{A}-Y_{P}\right)
$$

Model efficiency

$$
M E=1-\frac{\sum_{i=1}^{n}\left(Y_{A}-Y_{P}\right)^{2}}{\sum_{i=1}^{n}\left(Y_{A}-\bar{Y}_{A}\right)^{2}}
$$

\section{Results and Discussion}

Before developing the ANN model, the input and output sample data must be normalized between -1 and 1 for accuracy of prediction. The following equation is used to normalize data between -1 and 1 .

$$
Y=\frac{Y_{i}-Y_{\min }}{Y_{\max }-Y_{\min }}\left(\text { High }_{\text {value }}-\text { Low }_{\text {value }}\right)+\text { Low }_{\text {value }}
$$

where $Y$ is experimental data. 
In MLP and GRNN model, the six numbers of input variables such as: $m, W_{s}, T_{a}, T_{i}, T_{m}$ and $I$ in input layer and the output variable as thermal efficiency $\left(\eta_{t h}\right)$ in output layer are used. The ranges of experimental data sets are given in Table.3.

Table 3 Range of experimental data sets of present work

\begin{tabular}{|c|c|c|}
\hline Parameter & Min & Max \\
\hline Input: $m(\mathrm{~kg} / \mathrm{s})$ & 0.0100 & 0.0225 \\
\hline$W_{s}(\mathrm{~m} / \mathrm{s})$ & 0.63856 & 4.50566 \\
\hline$T_{a}\left({ }^{o} \mathrm{C}\right)$ & 28.200 & 34.800 \\
\hline$T_{i}\left({ }^{o} \mathrm{C}\right)$ & 29.000 & 37.330 \\
\hline$T_{m}\left({ }^{o} \mathrm{C}\right)$ & 33.845 & 49.030 \\
\hline$I\left(\mathrm{~W} / \mathrm{m}^{2}\right)$ & 682.750 & 963.35 \\
\hline Output: $\eta_{\text {th }}$ & 0.42371 & 0.64173 \\
\hline
\end{tabular}

\subsection{Predicting thermal performance using MLP model}

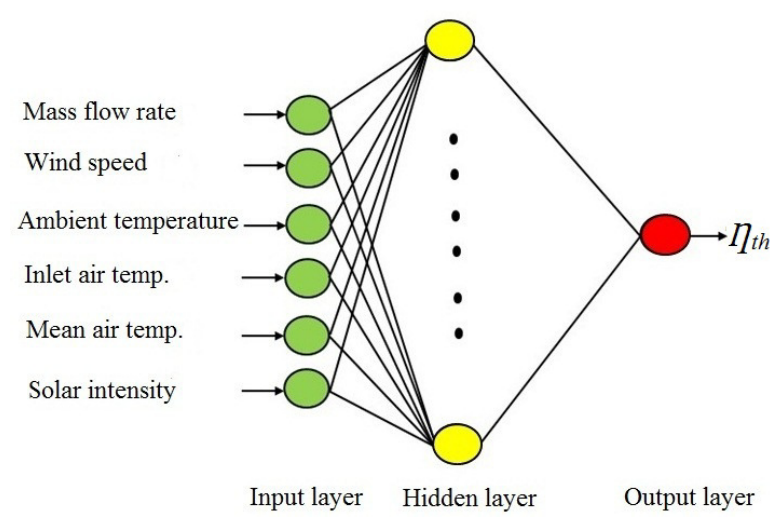

Figure 5 Proposed design of MLP model

The main objective of MLP model is to predict the performance of the SAH by using input and output data sets. Total 96 sets of data are used in this model, in which first 48 data sets of type A and rest 48 data sets of type $B$ screen matrices. Out of 96 data sets , $70 \%$ data were used to training and $30 \%$ for testing and validation. The MLP model of present work is shown in Fig. 5. Six parameters are used in input layer and one parameter is used in output layer. Single hidden layer is used in present model. For training process 10 to 15 neurons are selected in the hidden layer to find out optimum model. Before data sets are trained, training functions is selected. In present work LM learning algorithms has been selected. After selecting the training algorithm, the adaptive training function was selected (LEARNGDM). Tansig transfer function was selected for hidden layer and linear function (pureline) for output layer. In training process the training algorithm adjusts the weights and biases iteratively to minimize the deviation between actual and predicted values.

The statistical error analysis of MLP model with 10 to 15 numbers of neuron is shown in Fig. 6. The performance of MLP model is based on MSE, COV and R values. It has been found that LM-13 based model is optimum model due to lowest error and highest value of correlation coefficient found as compared to other neurons. The values of MSE, COV and R are 7.431E-06, 0.511412 and 0.99854 respectively found at LM-13. The value of MSE is calculated by Eq. (9), and remaining statistical parameters COV and $\mathrm{R}$ are calculated by following equations:

Coefficient of variance (COV):

$$
C O V=\frac{R M S E}{\frac{1}{n} \sum_{i=1}^{n} Y_{P}} \times 100
$$

Correlation coefficient (R):

$$
R=\frac{\sum_{i=1}^{n}\left(Y_{P}-\bar{Y}_{P}\right)\left(Y_{A}-\bar{Y}_{A}\right)}{\sqrt{\sum_{i=1}^{n}\left(Y_{P}-\bar{Y}_{P}\right)^{2}\left(Y_{A}-\bar{Y}_{A}\right)^{2}}}
$$


The predicted result of MLP is represented by graph in Fig.7 and its individual errors are shown in Fig.8. It has been found that most of the errors are in between \pm 0.0025 .

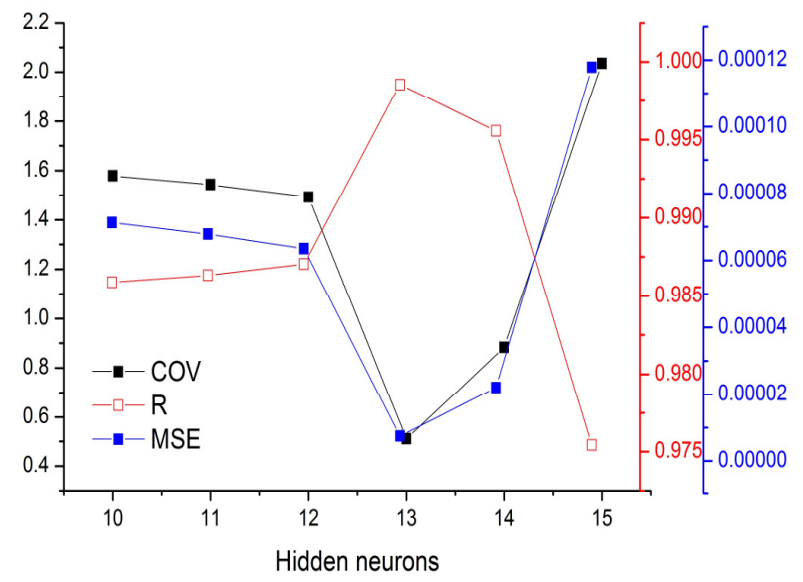

Figure 6 Statistical error analysis of MLP model

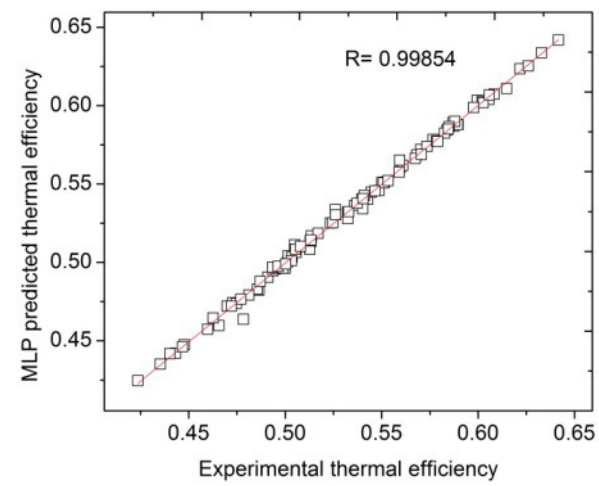

Figure 7 Comparison of experimental thermal efficiency with MLP predicted thermal efficiency.

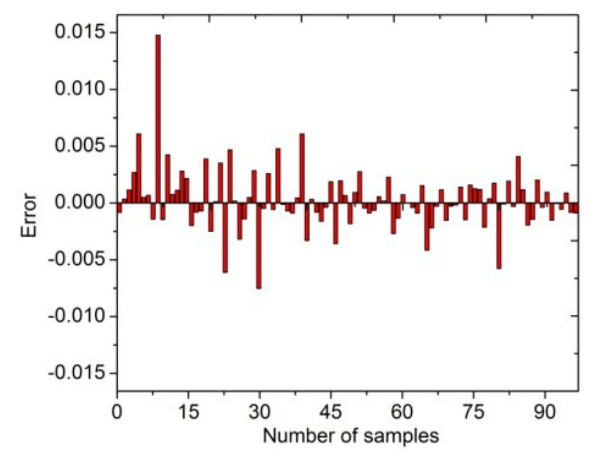

Figure 8 Individual error of MLP model's result

\subsection{Predicting thermal performance using GRNN model}

Same parameters of MLP model are used in GRNN model for predicting the performance of SAH. Same 96 data sets are used for simulation in GRNN. The GRNN model simulated with different spread constant 0.8, 1.0, 1.2 and 1.4. The statistical error analysis of simulated results is shown in Table 4. From Table 4, it has been found that at spread constant 0.8 predicted results are satisfactory due to lowest error and highest value of $\mathrm{R}$ as compare to other spread constant. The values of MSE and COV at spread constant 0.8 are 5.9284E-06 and 0.45658 respectively, and the value of $R$ is 0.99881 which is very close to unity. The comparison and individual error graphs are shown in Fig.9 and Fig.10 respectively.

Table 4 Statistical error analysis of GRNN model

\begin{tabular}{|c|c|c|c|}
\hline \multirow{2}{*}{$\begin{array}{c}\text { Spread } \\
\text { consta } \\
\text { nt }\end{array}$} & \multicolumn{3}{|c|}{ Statistical parameters } \\
\cline { 2 - 4 } & MSE & COV & R \\
\hline 0.8 & $5.9284 \mathrm{E}-06$ & 0.45658 & 0.99881 \\
\hline 1 & $1.5203 \mathrm{E}-05$ & 0.73131 & 0.99684 \\
\hline 1.2 & $3.2083 \mathrm{E}-05$ & 1.06216 & 0.99311 \\
\hline 1.4 & $5.5520 \mathrm{E}-05$ & 1.39971 & 0.98746 \\
\hline
\end{tabular}

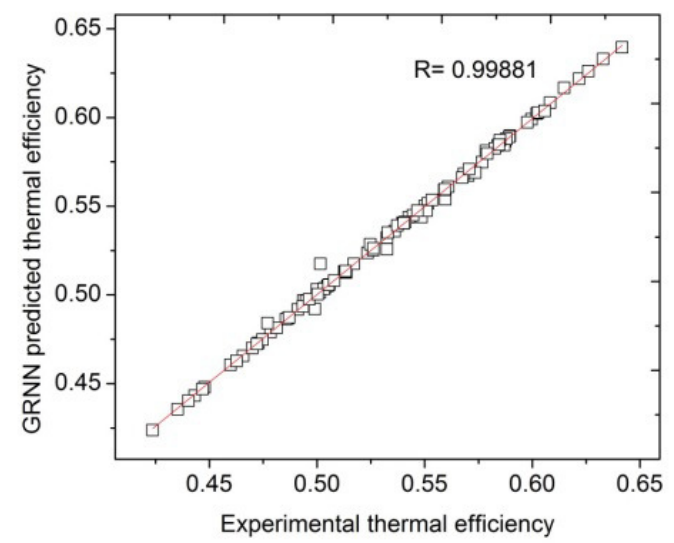

Figure 9 Comparison of experimental thermal efficiency with GRNN predicted thermal efficiency. 


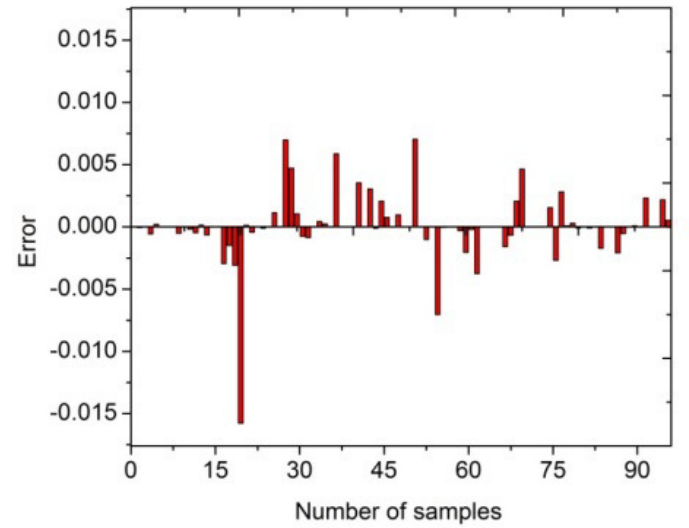

Figure 10 Individual error of GRNN model's result

\subsection{Comparative analysis of MLP and GRNN model performance}

The MLP and GRNN models have been used to predict the thermal performance of porous bed SAH. The comparisons of both the models are shown in Table 5. From this Table 5, it has been found that GRNN model is better than MLP model, due to lowest error and highest value of $\mathrm{R}^{2}$. It has also been found that ME greater than MLP models. The value of MAE for MLP and GRNN models are 1.8299E-03 and 1.1128E-03 respectively has been obtained. Similarly the values of RMSE are 7.4315E-06, and 5.9284E06 respectively, and the values of coefficient of determination are 0.99705 and 0.99758 respectively.

The above results show that both the models can successfully predict the thermal efficiency, but GRNN model predicts results with less error as compared to MLP model.

Fig 11 shows the comparisons of predicted results and actual thermal efficiency of MLP and GRNN model, and its individual error of each sample of both models are shown in Fig 12. It has been found that GRNN individual errors are the lower error as compare to MLP model
Table 5 Comparison of MLP and GRNN model to predict the thermal efficiency of SAH.

\begin{tabular}{|l|c|c|}
\hline \multirow{2}{*}{$\begin{array}{l}\text { Statistical } \\
\text { parameters }\end{array}$} & \multicolumn{2}{|c|}{ Types of model } \\
\cline { 2 - 3 } & GRNN & MLP \\
\hline MAE & $1.11 \mathrm{E}-03$ & $1.83 \mathrm{E}-03$ \\
\hline RMSE & $5.93 \mathrm{E}-06$ & $7.43 \mathrm{E}-06$ \\
\hline ME & 0.9976 & 0.99708 \\
\hline $\mathrm{R}^{2}$ & 0.99758 & 0.99705 \\
\hline
\end{tabular}

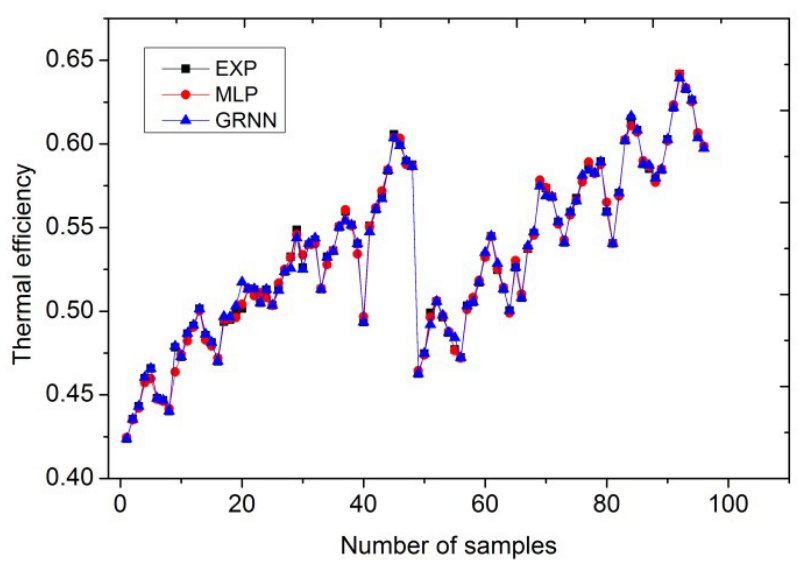

Figure 11 Comparison of experimental data with MLP and GRNN model predicted data.

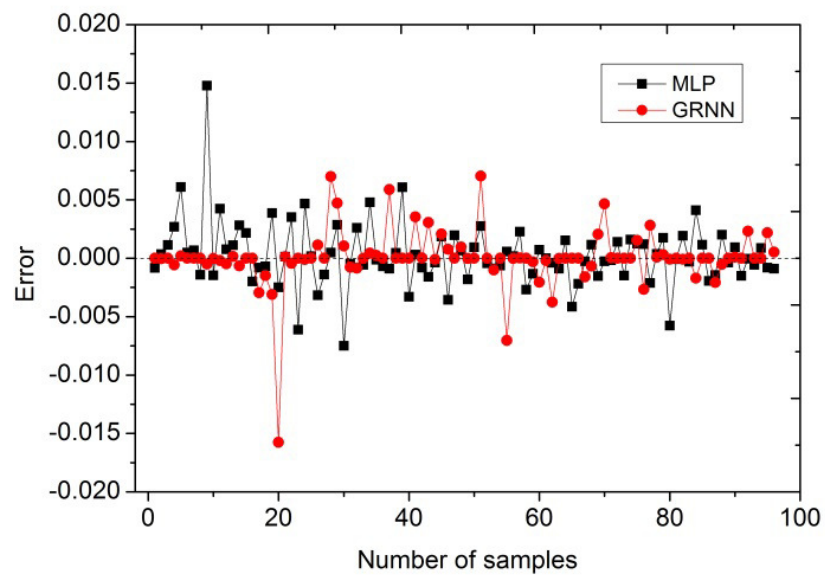

Figure 12 Individual error of MLP and GRNN model predicted data

\section{Conclusion}

In the present work, two different types of neural models (MLP and GRNN) have been used to predict the thermal performance of unidirectional flow porous bed solar air heater. 
Six input parameters were used in input layer and one parameter in output layer in both the models. Total 96 data sets were used. The following conclusions have been drawn:

1. It has been found that LM learning functions with 13 neurons is optimal MLP model for prediction.

2. GRNN, at spread constant 0.8 was found as optimal model.

3. The GRNN model is best model to predict the thermal performance of solar air heater as compare to MLP model, due to lowest error found and highest value of $\mathrm{R}^{2}$.

4. The value of MAE, RMSE and ME for GRNN model are obtained as 1.1128E-03, 5.9284E-06 and 0.99760 respectively.

5. The values of $\mathrm{R}^{2}$ have been found as 0.99705 and 0.99758 of MLP and GRNN model respectively.

\section{References}

[1]. Duffie, J.A., W.A. Beckman, W.A.,1991. Solar Engineering of Thermal Processes, Second ed. New York:Wiley Publication.

[2]. Tiwari, G.N., 2004. Solar Energy: Fundamentals, Design, Modelling and Applications", New Delhi, India: Narosa Publishing House.

[3]. Chiou, J.P., El-Wakil, M.M., Duffie, J.A., 1965. A slit-and -expanded aluminum-foil matrix solar collector, Sol. Energy 9, 7380.

[4]. Sharma, S.P., Saini, J.S., Varma, H.K., 1991. Thermal performance of packed bed solar air heaters, Solar Energy 47, 59- 67.

[5]. Prasad, R.K., Saini, J.S., 1993. Comparative performance study of packed bed solar air heaters, Emerging trends in Mechanical Engineering, In proceeding of the Eighth ISME Conference on Mech. Engg., I.I.T. Delhi, India, 190-197.

[6]. Prasad, R.K., Saini, J.S., 1993. Thermal performance characteristics of unidirectional flow porous bed solar energy collectors for heating air, Ph.D. Thesis, University of Roorkee, Roorkee, India.

[7]. Ahmad, Saini, J.S., Varma, H.K., 1995. Effect of geometrical and thermophysical characteristics of bed materials on the enhancement of thermal performance of packed bed solar air heaters, Energy Conv. Mgmt. 36, 1185-1195.

[8]. Varshney, L., Saini, J.S., 1998. Heat transfer and friction factor correlations for rectangular solar air heater duct packed with wire mesh screen matrices, Solar Energy 62 (4), 255-262.

[9]. Mittal, M.K., Varshney, L., 2006. Optimal thermohydraulic performance of a wire mesh packed solar air heater, Solar Energy 80, 1112-1120.

[10]. Omojaro, A.P., Aldabbagh, L.B.Y., 2010. Experimental performance of single and double pass solar air heater with fins and steel wire mesh as absorber, Applied Energy 87, 3759-3765.

[11]. Gardner, M.W., Dorling, S.R., 1998. Artificial Neural Networks (The Multilayer Perceptron): a review of applications in the atmospheric sciences. Atmos. Env. 32: 2627-2636.

[12]. Ben-Nakhi, A.E., Mahmoud, M.A., 2004. Cooling load prediction for buildings using general regression neural networks, Energy Conversion and Management 45, 21272141.

[13]. Facao, J., Szabolcs, V., Oliveira, A. C., 2004. Evaluation of the Use of Artificial Neural Networks for the Simulation of Hybrid Solar Collectors, International Journal of Green Energy 1(3), 337-352.

[14]. Kalogirou, S.A., 2006. Prediction of flatplate collector performance parameters using artificial neural networks, Solar Energy 80, 248-259.

[15]. Sozen, A., Menlik, T., Unvar, S., 2008. 
Determination of efficiency of flat-plate solar collectors using neural network approach, Expert Syst. Appl. 35(4), 15331539.

[16]. Kassem, A.S., Al-Sulaiman, M.A., Aboukarima, A.M., Kassem, S.S., 2011. Predicting drying efficiency during solar drying process of grapes clusters in a box dryer using artificial neural network, Aust. J. Basic Appl. Sci. 5, 230-241.

[17]. Caner, M., Gedikand, E., Kecebas, A., 2011. Investigation on thermal performance calculation of two type solar air collectors using artificial neural network, Expert Syst. Appl. 38(3), 1668-1674.

[18]. Benli, H., 2013. Determination of thermal performance calculation of two different types solar air collectors with the use of artificial neural networks, Int. J. of Heat and Mass Transfer 60, 1-7.

[19]. Sahin, M., Kaya, Y., Uyar, M., 2013. Comparison of ANN and MLR models for estimating solar radiation in Turkey using NOAA/AVHRR data, Adv. Space Res. 51, 891-904.

[20]. Çakmak, G., 2014. The water temperature prediction of a double exposure solar cooker, Environ. Prog. Sust. Energy 33, 629-635.

[21]. Citakoglu, H., 2015. Comparison of artificial intelligence techniques via empirical equations for prediction of solar radiation, Comput. Electron. Agric. 118, 28-37.

[22]. Mashalyand, A.F., Alazba, A.A., 2015. Comparative investigation of artificial neural network learning algorithms for modeling solar still production, J. Water Reuse Desalination 5 (4), 480-493.

[23]. Mashaly, A.F., Alazba, A.A., 2016. MLP and MLR models for instantaneous thermal efficiency prediction of solar still under hyper-arid environment, Computers and Electronics in Agriculture 122, 146-155.
[24]. Ghritlahre, H.K., Prasad , R.K., 2017. Prediction of thermal performance of unidirectional flow porous bed solar air heater with optimal training function using Artificial Neural Network, Energy Procedia 109, 369 - 376.

[25]. Ghritlahre, H.K., Prasad , R.K., 2017. Energetic and exergetic performance prediction of roughened solar air heater using artificial neural network, Ciência e Técnica Vitivinícola, 32 (11), 2-24.

[26]. Ghritlahre, H.K., Prasad , R.K., 2018. Application of ANN technique to predict the performance of solar collector systems A review, Renewable and Sustainable Energy Reviews 84, 75-88.

[27]. Ghritlahre, H.K., Prasad, R.K., 2018. Exergetic Performance Prediction of roughened Solar Air Heater Using Artificial Neural Network, Strojniški vestnik - Journal of Mechanical Engineering 64 (3), 195-206.

[28]. Ghritlahre, H.K., Prasad, R.K., 2018. Development of Optimal ANN Model to Estimate the Thermal Performance of Roughened Solar Air Heater Using Two different Learning Algorithms. Annals of Data Science 5(3), 453-467.

[29]. Ghritlahre, H.K., Prasad, R.K., 2018. Investigation on heat transfer characteristics of roughened solar air heater using ANN technique. International Journal of Heat and Technology 36 (1), 102-110.

[30]. Ghritlahre, H.K., Prasad, R.K., 2018. Investigation of thermal performance of unidirectional flow porous bed solar air heater using MLP, GRNN, and RBF models of ANN technique, Thermal Science and Engineering Progress 6, 226-235.

[31]. Ghritlahre, H.K., Prasad, R.K., 2018. Exergetic performance prediction of solar air heater using MLP, GRNN and RBF models of artificial neural network technique, Journal of Environmental Management 223, 566-575. 
[32]. Ghritlahre, H.K., Prasad, R.K., 2018. Prediction of exergetic efficiency of arc shaped wire roughened solar air heater using ANN model International Journal of Heat and Technology 36 (3), 1107-1115.

[33]. Ghritlahre, H.K., Prasad, R.K., 2018. Prediction of heat transfer of two different types of roughened solar air heater using Artificial Neural Network technique. Thermal Science and Engineering Progress. Volume 8, December 2018, Pages 145-153.

[34]. Ghritlahre, H. K., 2018. Development of feed-forward back-propagation neural model to predict the energy and exergy analysis of solar air heater, Trends in Renewable Energy, 4, 213-235. DOI: 10.17737/tre.2018.4.2.0078

[35]. Haykin, S., 1994. Neural networks, a comprehensive foundation, New Jersey: Prentice- Hall. 